BMJ

Open

Gastroenterology

\title{
Burnout in gastroenterology registrars: a feasibility study conducted in the East of England using a 31-item questionnaire
}

\author{
John Ong (D) ,1,2 Carla Swift, ${ }^{3}$ Sharon Ong (D) , ${ }^{4,5}$ Wan Yen Lim (D) ,,6 \\ Yasseen Al-Naeeb, ${ }^{3}$ Arun Shankar ${ }^{7}$
}

To cite: Ong J, Swift C, Ong S, et al. Burnout in gastroenterology registrars: a feasibility study conducted in the East of England using a 31-item questionnaire. BMJ Open Gastro 2020;7:e000401. doi:10.1136/ bmjgast-2020-000401

- Additional material is published online only. To view please visit the journal online (http://dx.doi.org/10.1136/ bmjgast-2020-000401).

Received 6 March 2020 Revised 5 June 2020 Accepted 10 June 2020

Check for updates

\section{(c) Author(s) (or their} employer(s)) 2020. Re-use permitted under CC BY-NC. No commercial re-use. See rights and permissions. Published by BMJ.

For numbered affiliations see end of article.

Correspondence to Dr John Ong; j0401@cam.ac.uk

\section{ABSTRACT}

Objective The scale of burnout in UK gastroenterology trainees and the feasibility to determine its prevalence using the validated Maslach Burnout Inventory-Human Services Survey (MBI-HSS) tool are unknown. The primary objective of this region-wide pilot study was to evaluate the response rate to a 31 -item questionnaire. The secondary objectives were to estimate the prevalence of burnout in gastroenterology trainees within the East of England deanery (EoE) and identify common stressors that trainees experience.

Design This was a cross-sectional study involving gastroenterology trainees from 16 hospitals across the EoE using a 31-item questionnaire. The questionnaire consisted of the 22-item MBI-HSS and nine additional free-text questions. All gastroenterology trainees in the EoE were invited to complete the anonymised survey online. Data were analysed quantitatively and qualitatively. Results The response rate for the survey was acceptable: $44.0 \%$ (40/91). $57.5 \%$ (23/40) of gastroenterology trainees reported emotional exhaustion. $23.5 \%(8 / 34)$ had depersonalisation and $63.9 \%$ (23/36) experienced low professional accomplishment. Burnout prevalence was $35.3 \%$ (12/34). $48.4 \%$ (15/31) of gastroenterology trainees were aware of professional support services within EoE. Stressors related to service requirements (eg, workload, staffing levels) and professional relationships with colleagues and patients were commonly reported: $65.6 \%$ and $25.0 \%$, respectively.

Conclusions It is feasible to use a 31-item questionnaire in a national cohort of UK gastroenterology trainees for future burnout studies. Burnout in EoE gastroenterology trainees was high and this may reflect a national prevalence within the specialty. More extensive studies, greater awareness of burnout and improved access to professional support services are required.

\section{INTRODUCTION}

Burnout is an occupational hazard that is recognised as an 'occupational phenomenon' in the 11th revision of the International Classification of Disease (ICD). 30\%-50\% of clinicians are estimated to have burnout symptoms. ${ }^{1}$ Burnout is typically characterised
Summary box

What is already known about this subject?

- Burnout in physicians, which can lead to personal ill-health and suboptimal patient care, is a growing problem worldwide.

- Burnout in gastroenterology fellows in the USA has been reported to be as high as $50 \%$; however, the prevalence in UK gastroenterology trainees (ie, registrars) is unknown.

- The Maslach Burnout Inventory-Human Services Survey (MBI-HSS) is the most validated tool to determine physician burnout; however, survey length may affect response rates of UK gastroenterology trainees and the feasibility of future studies.

What are the new findings?

- This pilot study demonstrated the feasibility of a 31item questionnaire which included the MBI-HSS in assessing burnout in UK gastroenterology trainees.

- Emotional exhaustion and a sense of low personal accomplishment affect more than half of gastroenterology trainees within the East of England (EoE).

- The prevalence of burnout in UK gastroenterology trainees is estimated to be high (35.3\%); however more extensive studies are required.

- Approximately half of gastroenterology trainees in the EoE were not aware of existing support services to assist them in coping with burnout.

How might it impact on clinical practice in the foreseeable future?

- This pilot study may increase awareness of burnout among UK trainees and trainers in gastroenterology.

- An estimate of burnout prevalence in UK gastroenterology trainees is included to justify future research and remediation measures in the specialty.

by symptoms of emotional exhaustion (EE), depersonalisation (DP) and a sense of low personal accomplishment (LPA); the latter two domains have also been referred to as 'cynicism' and 'reduced professional efficacy', respectively. ${ }^{2}$ Symptoms exist on a scale of varying severity and lack of awareness 
can lead to its under-recognition. ${ }^{3}$ Unaddressed, clinician burnout can negatively impact patient outcome through impaired professionalism, poor communication, decreased patient satisfaction, professional errors and patient harm. ${ }^{1}$ Burnout is also associated with depression, suicidal ideations, sleep disturbances, alcoholism, musculoskeletal disorders, hypertension and ischaemic heart disease. ${ }^{4-7}$ Nonetheless, it can be alleviated or reversed and well-placed support mechanisms are vital to preserving the mental well-being of clinicians in distress, ${ }^{18}$ especially those in the early stages of their careers. $^{3}$

Gastroenterology involves heavy workloads and large volumes of patients. Unsurprisingly burnout in young gastroenterologists in the USA has been reported to be as high as $54 \% .^{3}$ In the UK, the prevalence of burnout in gastroenterology trainees is under studied and the scale of the issue remains unknown. Several tools have been developed to detect burnout, for example, the 22-item Maslach Burnout Inventory-Human Services Survey (MBI-HSS), the 19-item Copenhagen Burnout Inventory and the 16-item Oldenburg Burnout Inventory. ${ }^{9} 10$ The MBI-HSS is the most extensively validated and widely used tool to study medical professionals. ${ }^{11}$ However, when the 22-item MBI-HSS is supplemented with additional questions (eg, demographic data), the resulting questionnaires are extensive and often yield low response rates. ${ }^{12}$ We designed a 31-item questionnaire containing the 22-item MBI-HSS and nine free-text questions. It was unknown whether the response rate of UK gastroenterology trainees to a questionnaire of this length would be adequate for meaningful data analysis; typical response rates for US-based studies of gastroenterologists range from $8.1 \%$ to $12 \% .{ }^{31314}$ A recent 64 -item survey on stress in UK gastroenterologists yielded a response rate of $29 \% .^{15}$

We hypothesised our streamlined 31-item questionnaire could accurately detect burnout, provide useful respondent information and achieve adequate response rates. The primary objective of this study was to evaluate the response rate to our questionnaire before extending the study nationally. The secondary objectives were to estimate burnout prevalence within the East of England (EoE) deanery and understand common stressors in respondents. A response rate of $>30 \%$ was defined as acceptable; this is higher than typical response rates in un-incentivised studies of burnout. ${ }^{16}$

\section{METHODS}

\section{Ethics}

Prior to designing the survey, the authors completed the Medical Research Council and NHS Health Research Authority decision tool (www.hra-decisiontools.org.uk) which determined that ethical approval from a local research ethics committee (REC) was not required (online supplementary appendix 1). All participants were automatically anonymised by the online survey platform and trainees were advised of this in their invitation email. Trainees were informed the survey was for research purposes and participation was voluntary. Completion of the survey conferred implied consent and the authors received anonymised responses with no information identifying trainees. There were no risks posed to participants and participation in the survey was not incentivised.

\section{Terminology}

For readers unfamiliar with the UK gastroenterology training system, the terms gastroenterology 'registrars' and 'trainees' are used interchangeably. Standard specialty training in gastroenterology within the UK spans 5 years of full-time clinical training: ST3 (first year of specialist training), ST4, ST5, ST6 and ST7 (last year of training before certification as a specialist). A 'deanery' refers to the organisation responsible for postgraduate medical training within a region in the UK. The EoE is responsible for postgraduate medical training across six counties in England.

\section{Design and administration of the questionnaire}

A two-part questionnaire was designed to detect the presence of burnout and collect individual data for further analyses. The first part comprised the 22-question MBIHSS which assessed burnout symptoms in the domains of EE, DP and a sense of LPA. A license to reproduce the MBI-HSS electronically was obtained (www.mindgarden.com). The second part comprised nine free-text questions which followed the MBI-HSS. The 31 questions in total were transcribed to an online platform (www. surveymonkey.co.uk). For ease of data processing, the entire questionnaire was divided into four pages: page 1 contained nine questions on EE, page 2 contained eight questions on LPA, page 3 contained five questions on DP and page 4 contained the nine free-text questions.

The nine free-text questions (online supplementary table 1) gathered demographic data in addition to information on the most significant stressors that trainees perceived. It is common practice for burnout studies to have additional questions because burnout inventories alone only inform if respondents are burned out or not burned out. The addition of these nine questions enabled the authors to gain a better understanding of the contributors to trainee burnout and enabled the investigation of common demographic variables and their associations with burnout, for example, years in practice and clinician burnout. Of the nine questions, one question on general internal medical (GIM) on calls was included because it is widely accepted that the role of acute medical registrar in the UK is a highly demanding and stressful responsibility, ${ }^{17}$ and therefore, may have had an effect on burnout rates.

An electronic link to the questionnaire was circulated to all 91 gastroenterology trainees within the EoE via work and personal email, and data were collected between 15 January and 15 February 2020. A reminder email was sent 
on 29 January 2020. All responses were anonymised. To preserve respondent anonymity, telephone reminders were not used.

\section{Analysis of MBI-HSS scores}

Each question in the MBI-HSS was graded on a 7-point Likert scale according to the frequency of symptoms, ranging from 'never' (0) to 'every day' (6). The Cronbach's alpha in each domain was greater than 0.7 . Two methods, 'method 1' and 'method 2', were used in the analysis and reporting of MBI scores. Method 1 involves the summation of question scores in each domain and is classically used in burnout studies. Therefore, to identify burnout, summated scores were used (method 1$){ }^{18}$ Burnout was defined as the presence of either a high summated EE score with a high summated DP score or a high summated EE score with a low summated LPA score (summated EE $\geq 27$ and summated DP $\geq 13$ or summated EE $\geq 27$ and summated LPA $\leq 31) .{ }^{18} 19$ These criteria for burnout were chosen because they are the only MBIassociated criteria that have been clinically validated against symptoms in the ICD (WHO), and they have been supported by Maslach et al. ${ }^{18} 19$

Although method 1 has been traditionally used to identify burnout, previous cut-off values associated with method 1 that delineated low, medium and high risk of burnout were arbitrary and, therefore, method 2 was recently developed by Maslach et al. ${ }^{18}$ Method 2 involves the averaging of scores across each domain and reflects symptom frequency; abnormal cut-offs for symptom frequency were provided by the MBI manual (proprietary). The method remains valid even if response to domain questions are incomplete. ${ }^{18}$ Briefly, abnormal cut-offs were derived from a population of 6269 healthcare workers using the following formulae: abnormal $\mathrm{EE}=$ mean $+(\mathrm{SD} \times 0.5), \quad$ abnormal $\quad \mathrm{DP}=$ mean $+(\mathrm{SD} \times 1.25)$ and abnormal $\mathrm{LPA}=\mathrm{mean}+(\mathrm{SD} \times 0.1) .{ }^{18}$ The higher the average score in the EE and DP subscales, the more frequent and severe the symptoms. Conversely, in the subscale measuring LPA, the lower the average score, the more severe the symptoms. Although seemingly more informative than method 1 , absolute cut-off values and the necessary combinations of abnormal domains to define burnout clinically using method two have not been researched and validated. Nonetheless, both methods have been recommended in the fourth edition of MBI manual to study burnout. ${ }^{18}$ For this reason, method 2 was only used to determine how many gastroenterology registrars experienced abnormal burnout symptoms and gauge symptom severity.

From the respondents that had abnormal symptoms of EE, DP and LPA identified by method 2, we used frequency of symptoms to classify severity as 'mild to moderate' or 'severe'. Abnormal symptoms of EE and DP occurring at a frequency of once per week or more often (domain average score $\geq 4$ ) were defined as severe; symptoms occurring less frequently; however, still identified as abnormal by the MBI manual were defined as mild to moderate. Conversely for LPA, respondents that did not have any positive feelings or experiences in their work once per week or more often (domain average score $<4$ ) were defined as severe. The remaining respondents with abnormal LPA scores were classified as mild to moderate.

\section{Analysis of qualitative data}

The questions in the second part of the questionnaire were analysed quantitatively and qualitatively. Trainees were asked for the most significant job-related factor that contributed to their stress levels. Their responses were grouped under the most appropriate of the four themes: service requirements (eg, workload, staffing levels), professional relationships (with colleagues and patients), training (eg, examinations, length of training, programme requirements) and others.

\section{Statistical analyses}

MedCalc V.19.1.5 was used to perform the statistical analyses. Trainee variables were tested for normality using the Shapiro-Wilk method where applicable. ${ }^{20}$ Parametric results were reported as mean \pm SD and nonparametric results were reported as median and IQR. The age of trainees between burned out and non-burned out groups did not follow a normal distribution so they were compared using the Mann-Whitney U test. Since there were low numbers of trainees $(n \leq 5)$ in at least one cell in all contingency tables, the Fisher's exact test was used to calculate $\mathrm{p}$ values for improved accuracy when comparing employment status (full-time vs less than fulltime), gender (men vs women), GIM on calls (yes vs no), training grades and training centres (tertiary centre, district general hospital (DGH) and research centre).

Two-tailed $\mathrm{p}$ values were reported for all tests and the significance level was set at 5\%. Bonferroni correction was applied for multiple hypothesis testing only if a significant $p$ value was obtained. Regression models were not used because the small sample size would not provide accurate results for meaningful interpretation. ${ }^{21}$ A logistic regression model to identify relationships between trainee associated variables and burnout will be used in a planned national study where the sample size will be considerably larger.

\section{Patient and public involvement}

This study did not involve any patients or members of the public.

\section{Exclusion criteria and missing data}

Missing data from incomplete DP and LPA questions were not used in the calculation of burnout rates derived by method 1 (summated scores). Average DP and LPA scores were calculated from incomplete DP and LPA questions using method 2 as permissible and advised by product literature; average DP and LPA scores were used to determine symptom severity in cases with abnormal domain scores. Missing data from the second part of the survey were not included in the respective fields of 


\begin{tabular}{|c|c|}
\hline Trainee demographics & Results \\
\hline \multicolumn{2}{|l|}{ Age (years) } \\
\hline Median, IQR & $32,30-35$ \\
\hline Mean & 33.1 \\
\hline \multicolumn{2}{|l|}{ Training grade (\%) } \\
\hline ST3 & 16.7 \\
\hline ST4 & 23.3 \\
\hline ST5 & 16.7 \\
\hline ST6 & 30 \\
\hline ST7 & 13.3 \\
\hline
\end{tabular}

Full-time training (\%)

\begin{tabular}{ll} 
Yes & 87.9 \\
\hline No & 12.1 \\
Gender (\%) & 71 \\
Male & 29 \\
Female & \\
Training centres (\%) & 53.1 \\
DGH & 43.8 \\
Tertiary & 3.1 \\
Research centre & \\
\hline GIM oncalls (\%) & 87.5 \\
Yes & 12.5 \\
\hline No & \\
\hline
\end{tabular}

DGH, district general hospital; GIM, general internal medicine.

analysis. All authors in this paper were excluded from this study.

\section{RESULTS}

\section{Response rate}

The response rate of the questionnaire was adequate and a response rate of $44.0 \%$ (41/90) was achieved. $62.5 \%$ $(25 / 40)$ of all responses were received within the first 2 weeks of the survey, 35\% (14/40) of responses were received within 1 week of the reminder email being sent and $2.5 \%(1 / 40)$ of responses were received in the last week of the survey. There was a $100 \%$ (40/40) completion rate for questions on EE, a $90.0 \%$ (36/40) completion rate for questions on LPA and an $85.0 \%$ (34/40) completion rate for questions on DP. For the second part of the questionnaire, $65.0 \%(26 / 40)$ of respondents completed all nine questions.

\section{Demographics of respondents}

Most gastroenterology trainees who responded to the survey were aged between 30 and 35 years old with the mode of respondents being ST6. There were approximately 2.4 times more male respondents than female respondents, and there were slightly more gastroenterology trainees who were working in DGHs than tertiary

\section{$\%$ of respondents}

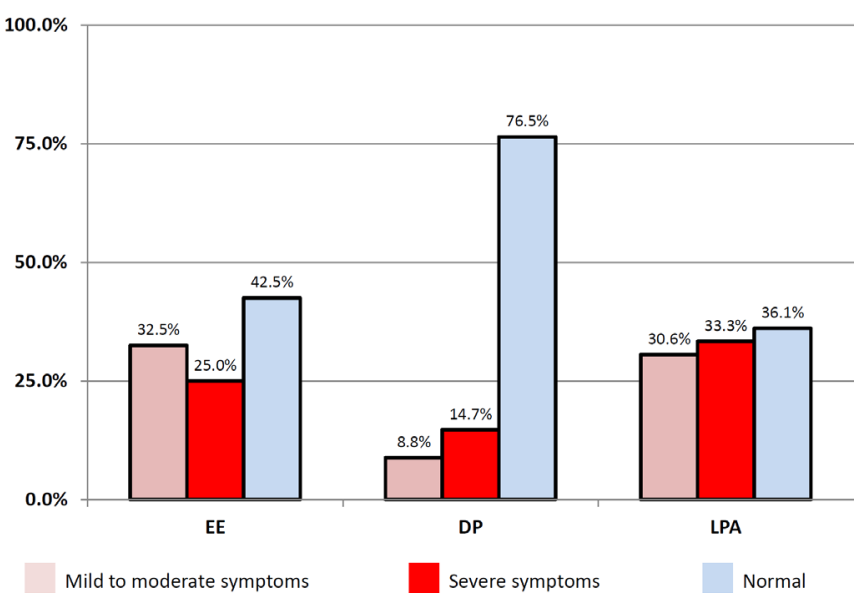

Figure 1 Frequency of burnout symptoms among gastroenterology trainees in the East of England. EE, emotional exhaustion; DP, depersonalisation; LPA, low personal accomplishment.

centres $(43.8 \%$ vs $53.1 \%)$. Most of the gastroenterology trainees were involved in GIM on calls. A summary of the demographic data is displayed in table 1.

\section{Estimated prevalence of burnout and burnout-related symptoms were high in gastroenterology trainees}

Burnout was present in $35.3 \%(12 / 34)$ of gastroenterology trainees and the prevalence of burnout-related symptoms was also high (figure 1). EE was present in $57.5 \%(23 / 40)$ of all respondents (EE mean $3.9 \pm 0.8)$. Of these, $43.5 \%(10 / 23)$ experienced symptoms once per week or more frequently. DP was detected in $23.5 \%$ $(8 / 34)$ of all trainees (DP mean $3.9 \pm 0.6$ ). Of those trainees, $62.5 \%(5 / 8)$ experienced symptoms once per week or more frequently. $63.9 \%(23 / 36)$ of all respondents experienced abnormal LPA (LPA mean 3.8 \pm 0.7 ). Of those respondents, $52.2 \%(12 / 23)$ had feelings of competence and successful achievement at work once per week or less often. Despite the high prevalence of burnout symptoms, only $48.4 \%(15 / 31)$ of gastroenterology trainees were aware that there were professional support services within the deanery to assist trainees in distress.

\section{Characteristics of burned out gastroenterology trainees}

A summary of the characteristics between burned out and non-burned out gastroenterology trainees are displayed in table 2. For research purposes, the summated subscale scores were calculated and the results for the burned out group were as follows: EE=34.0 (median: 32, IQR 29-40), $\mathrm{DP}=16.3 \pm 7.4$ and $\mathrm{LPA}=28.2 \pm 7.2$. For the non-burned out group, the results of the summated subscale scores were $\mathrm{EE}=21.2 \pm 10.8, \mathrm{DP}=7.6$ (median: 6 , IQR 5-10) and $\mathrm{LPA}=38.0 \pm 5.4$.

\section{Common stressors in UK gastroenterology trainees}

$87.1 \%(27 / 31)$ of gastroenterology trainees stated that job-related factors contributed to the greatest amount 
Table 2 Characteristics of burned out and non-burned out gastroenterology trainees

\begin{tabular}{|c|c|c|c|}
\hline \multirow{2}{*}{$\begin{array}{l}\text { Trainee } \\
\text { variable }\end{array}$} & Burned out & $\begin{array}{l}\text { Non-burned } \\
\text { out }\end{array}$ & \multirow[b]{2}{*}{ (a) versus (b) } \\
\hline & (a) & (b) & \\
\hline $\begin{array}{l}\text { Median age in } \\
\text { years (IQR) }\end{array}$ & $34(32-35)$ & $32(30-35)$ & $p=0.15$ \\
\hline \multicolumn{2}{|l|}{ Grade (\%) } & & $p=0.15$ \\
\hline ST3 & $20.0(1 / 5)$ & $80.0(4 / 5)$ & \\
\hline ST4 & $14.3(1 / 7)$ & $85.7(6 / 7)$ & \\
\hline ST5 & $80.0(4 / 5)$ & $20.0(1 / 5)$ & \\
\hline ST6 & $55.6(5 / 9)$ & $44.4(4 / 9)$ & \\
\hline ST7 & $25.0(1 / 4)$ & $75.0(3 / 4)$ & \\
\hline \multicolumn{2}{|c|}{ Employment status (\%) } & & $p=0.27$ \\
\hline Full-time & $41.4(12 / 29)$ & $58.6(17 / 29)$ & \\
\hline LTFT & $0(0)$ & $100(4 / 4)$ & \\
\hline \multicolumn{2}{|l|}{ Gender (\%) } & & $p=0.70$ \\
\hline Male & $40.9(9 / 22)$ & $59.1(13 / 22)$ & \\
\hline Female & $33.3(3 / 9)$ & $66.7(6 / 9)$ & \\
\hline \multicolumn{2}{|c|}{ Training centre (\%) } & & $p=0.27$ \\
\hline Tertiary & $42.9(6 / 14)$ & $57.1(8 / 14)$ & \\
\hline DGH & $29.4(5 / 17)$ & $70.6(12 / 17)$ & \\
\hline $\begin{array}{l}\text { Research } \\
\text { centre }\end{array}$ & $100(1 / 1)$ & $0(0 / 0)$ & \\
\hline \multicolumn{2}{|c|}{ GIM on calls (\%) } & & $p=0.49$ \\
\hline Yes & $32.1(9 / 28)$ & $67.9(19 / 28)$ & \\
\hline No & $50.0(2 / 4)$ & $50.0(2 / 4)$ & \\
\hline
\end{tabular}

$\mathrm{DGH}$, district general hospital; GIM, general internal medicine; LTFT, less than full time.

of stress in their lives and $12.9 \%$ (4/31) reported that personal factors (family relationships and personal finances) contributed to the greatest amount of stress in their lives. Figure 2 illustrates the frequency of jobrelated stressors reported by gastroenterology trainees according to the themes. Stressors related to service requirements consisted of workload $(56.2 \%)$ and inadequate staffing levels $(9.4 \%)$. Stressors in professional

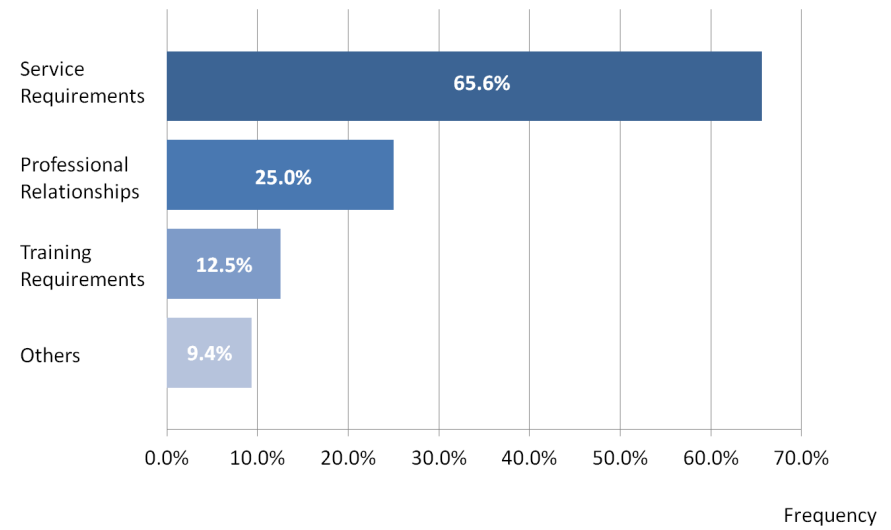

Figure 2 The frequency of significant stressors reported by gastroenterology trainees and grouped by common themes. relationships consisted of difficult and unsupportive colleagues $(9.4 \%)$, expectations of seniors $(9.4 \%)$, difficult patients $(3.1 \%)$ and expectations of patients $(3.1 \%)$. Stressors related to training requirements comprised specialty examinations $(6.3 \%)$, length of training $(3.1 \%)$ and curriculum requirements $(3.1 \%)$. Other stressors reported included long commuting times between home and work $(6.3 \%)$ and length of specialty training $(3.1 \%)$.

\section{DISCUSSION}

This study has demonstrated the feasibility of the 31-item questionnaire in assessing burnout in UK gastroenterology trainees; a response rate of $44.0 \%$ was achieved which is higher than commonly reported response rates in burnout studies. There were also significantly more male than female respondents in our study; however, this reflects the number of female gastroenterologists (including gastroenterology trainees) within the UK $(21 \%-39 \%) .^{22}$ Our study estimated the prevalence of burnout to be $35.3 \%$ whereas US studies on gastroenterologists have reported a range of $37 \%-50 \% .^{3}$ However, direct statistical comparisons with large-scale US studies of burnout in gastroenterology are not appropriate at present because of differences in study populations and criteria used to define burnout. ${ }^{13}{ }^{14}$ Statistically significant associations between burnout and respondent age, training grades, employment status, training centres and GIM on calls were not observed. However, the lack of statistical significance does not imply a lack of association but rather that associations may not have been detected because of the small sample size. In the planned nationwide study, these factors could be analysed more meaningfully in a larger sample size with regression methods to test for associations.

Additionally, the fact that difficult and unsupportive colleagues was the second most frequently reported stressor $(9.4 \%)$ was unexpected and ranked jointly with expectations by seniors $(9.4 \%)$ and poor staffing levels $(9.4 \%)$. The two former stressors may be addressed by interventions such as mentoring and mindfulness-based exercises $^{23-26}$; however, the latter may prove to be more difficult for reasons discussed later. More importantly, we discovered that only $48.4 \%$ of all gastroenterology trainees were aware of existing professional support services within the EoE to assist trainees in distress. As a result, since the completion of the study, bespoke lectures on well-being and wider advertisement of support services have been planned for gastroenterology trainees within EoE.

In the UK, the demand for gastroenterology services is gradually increasing however almost half of all advertised gastroenterology consultant posts remain unfilled..$^{22}$ Several years are required to train or recruit manpower to fill these vacancies and it is, therefore, unsurprising that current gastroenterology consultants and trainees face heavy workloads and may experience high levels of stress and burnout. Recently, a survey on stress among 
UK gastroenterologists revealed that $48 \%$ of respondents considered leaving their current hospital of work, $44 \%$ had lost their temper at work and $6 \%$ had contemplated suicide. ${ }^{15}$ These results strongly suggest that additional studies on burnout are required. This is especially true for UK gastroenterology trainees and young consultants since early-stage burnout can diminish the size of the future workforce, negatively impact its sustainability and have detrimental effects on the health of patients and clinicians. Once a nationwide study of gastroenterology trainees has been completed, the authors intend to conduct similar studies on the remainder of the UK gastroenterology workforce including gastroenterology consultants, nurses and allied health professionals. This will facilitate the study of burnout among the workforce, and awareness of, and access to, support services across the country.

This study used the 22-item MBI-HSS to detect burnout although abbreviated versions (aMBI) of the tool exist. These include the 2-item and 9-item MBI, and the 12-item aMBI which are favoured by some researchers because they are easier to administer and can yield better response rates. However, we have chosen not to use an abbreviated version of the MBI because these can be unreliable; we have previously demonstrated that the 12-question MBI had a poor positive predictive value of $33.3 \%$ (95\% CI $27.5 \%-39.8 \%$ ) and could overestimate the prevalence of burnout. ${ }^{27}$ Although the MBI-HSS is a well-established tool, many researchers have adopted alternative criteria in addition to numerical cut-off values to define burnout. Such heterogeneity in burnout definitions, as well as burnout tools, has precluded the accurate estimation of burnout in systematic reviews and meta-analyses. ${ }^{11}{ }^{28}$ In this study, burnout was defined by the Maslach-supported criteria of 'high EE and high DP' or 'high EE and low PA' since this is the only definition that has been shown to have a clinical correlation. Researchers have established that the combination of high scores in these domains correlate closely to work-related neurasthenia as defined by ICD-10. ${ }^{181929}$ Using this definition, the prevalence of clinical burnout was determined to be $35.3 \%$; however, this may be an underestimation because burned out trainees may not have engaged in this study.

The study period was capped at 1 month because given our experience in burnout studies of similar sample size, most responses were typically obtained within the first 2 weeks of the survey. ${ }^{27}$ This is evidenced in our observations of the current study as shown in the results. For the planned nationwide study, the study period will be extended to 3 months since the cohort size will be exponentially larger.

This pilot study had several limitations. Being a voluntary survey, this study may have been affected by response bias and non-response bias although these are inherent problems of survey-based burnout studies. Moreover, the small sample size may not be fully representative of gastroenterology trainees throughout the UK, therefore, a more extensive study with a larger cohort size is needed to accurately determine the national prevalence of burnout. The sequence of MBI-HSS questions were re-ordered in the administration of the survey and there is a theoretical risk that it might have affected the MBI-HSS results; however, the authors previously demonstrated that the 12-item aMBI domain scores still maintained excellent correlation to the summated MBI-HSS domain scores despite the omission of nine questions. ${ }^{27}$ Although the MBI-HSS is the most reliable and validated tool to detect burnout to date, its limitation should be recognised because burnout syndrome itself is poorly characterised. Finally, working hours and rota patterns for gastroenterology and GIM were not studied and, therefore, limited insight can be gained into the working environment of gastroenterology trainees. The authors acknowledge this was a compromise to optimise response rates. Even though associations between longer working hours and burnout are known, the relationships are nonlinear, often complex and are influenced by many other factors such as personality traits (eg, resilience) which are difficult to measure.

\section{CONCLUSION}

It is feasible to use a 31-item questionnaire comprising the MBI-HSS to determine the prevalence of burnout in gastroenterology trainees in a larger cohort study. Most gastroenterology trainees within the EoE have symptoms of burnout and the prevalence of burnout was estimated at 35.3\%; however, larger-scale studies are required. Service requirements and professional relationships contribute the most stress in gastroenterology trainees in the EoE. Greater awareness of burnout and better access to professional support services are required.

\section{Author affiliations \\ ${ }^{1}$ Department of Engineering, University of Cambridge, Cambridge, UK ${ }^{2}$ Department of Medicine, National University of Singapore, Singapore ${ }^{3}$ Department of Gastroenterology, Bedford Hospital NHS Trust, Bedford, UK ${ }^{4}$ Department of Surgical Intensive Care, Singapore General Hospital, Singapore ${ }^{5}$ Department of Surgical Intensive Care, Sengkang General Hospital, Singapore ${ }^{6}$ Department of Anaesthesia, Singapore General Hospital, Singapore ${ }^{7}$ Department of Gastroenterology, Norfolk and Norwich University Hospitals NHS Foundation Trust, Norwich, UK}

Contributors Conceptualisation: J0; design: all authors; data curation: J0 and CS; data analysis: all authors; manuscript preparation: JO, CS and WYL; revisions: JO, CS, S0 and YA-N; critical edits and supervision: AS.

Funding J0 is funded by the W.D. Armstrong Doctoral Research Training Fellowship at the University of Cambridge and a Development Grant from the National University of Singapore.

Disclaimer This research was not funded; however, communications and access to literature were provided by the University of Cambridge.

Competing interests None declared.

Patient consent for publication Not required.

Provenance and peer review Not commissioned; externally peer reviewed.

Data availability statement All data relevant to the study are included in the article or uploaded as supplementary information.

Open access This is an open access article distributed in accordance with the Creative Commons Attribution Non Commercial (CC BY-NC 4.0) license, which permits others to distribute, remix, adapt, build upon this work non-commercially, 
and license their derivative works on different terms, provided the original work is properly cited, appropriate credit is given, any changes made indicated, and the use is non-commercial. See: http://creativecommons.org/licenses/by-nc/4.0/.

\section{ORCID iDs}

John Ong http://orcid.org/0000-0001-5103-7311

Sharon Ong http://orcid.org/0000-0001-9851-0401

Wan Yen Lim http://orcid.org/0000-0002-0335-0255

\section{REFERENCES}

1 West CP, Dyrbye LN, Erwin PJ, et al. Interventions to prevent and reduce physician burnout: a systematic review and meta-analysis. Lancet 2016:388:2272-81.

2 Maslach C, Leiter MP. Understanding the burnout experience: recent research and its implications for psychiatry. World Psychiatry 2016:15:103-11.

3 Barnes EL, Ketwaroo GA, Shields HM. Scope of burnout among young Gastroenterologists and practical solutions from gastroenterology and other disciplines. Dig Dis Sci 2019;64:302-6.

4 Shanafelt TD, Bradley KA, Wipf JE, et al. Burnout and self-reported patient care in an internal medicine residency program. Ann Intern Med 2002;136:358-67.

5 Peterson U, Demerouti E, Bergström G, et al. Burnout and physical and mental health among Swedish healthcare workers. J Adv Nurs 2008;62:84-95.

6 Shanafelt TD, Sloan JA, Habermann TM. The well-being of physicians. Am J Med 2003;114:513-9.

7 Jang ES, Park SM, Park YS, et al. Work-Life conflict and its health effects on Korean Gastroenterologists according to age and sex. Dig Dis Sci 2020;65:86-95.

8 Goldberg R, Boss RW, Chan L, et al. Burnout and its correlates in emergency physicians: four years' experience with a wellness booth. Acad Emerg Med 1996;3:1156-64.

9 Kristensen TS, Borritz M, Villadsen E, et al. The Copenhagen burnout inventory: a new tool for the assessment of burnout. Work Stress 2005;19:192-207.

10 Demerouti E, Bakker AB, Vardakou I, et al. The convergent validity of two burnout instruments: a multitrait-multimethod analysis. Eur $J$ Psychol Assess 2003;19:12

11 Rotenstein LS, Torre M, Ramos MA, et al. Prevalence of burnout among physicians: a systematic review. JAMA 2018;320:1131-50.

12 West CP, Dyrbye LN, Satele DV, et al. Concurrent validity of singleitem measures of emotional exhaustion and depersonalization in burnout assessment. J Gen Intern Med 2012;27:1445-52.
13 Keswani RN, Taft TH, Coté GA, et al. Increased levels of stress and burnout are related to decreased physician experience and to interventional gastroenterology career choice: findings from a US survey of endoscopists. Am J Gastroenterol 2011;106:1734-40.

14 Burke C, Surawicz CM, Oxentenko AS, et al. A national survey of burnout in Gastroenterologists. Am J Gastroenterol 2017:112:S593-4.

15 Gleeson D, O'Shea C, Ellison H, et al. Stress and its causes in UK Gastroenterologists: results of a national survey by the British Society of gastroenterology. Frontline Gastroenterol 2019;10:43-9.

16 Roberts DL, Shanafelt TD, Dyrbye LN, et al. A national comparison of burnout and work-life balance among internal medicine hospitalists and outpatient General internists. J Hosp Med 2014;9:176-81.

17 Blayney S, Crowe A, Bray D. Survival as medical registrar on call: remember the doughnut. Clin Med 2014;14:506-9.

18 Maslach C, Jackson S, Leiter M. Maslach burnout inventory. 4th Edn. Menlo Park, CA: Mind Garden, 2018: 10-74.

19 Dyrbye LN, West CP, Shanafelt TD. Defining burnout as a dichotomous variable. J Gen Intern Med 2009;24:440.

20 Shapiro SS, Wilk MB. An analysis of variance test for normality (complete samples). Biometrika 1965;52:591-611.

21 Hart RA, Clark DH. Does size matter? exploring the small sample properties of maximum likelihood estimation. Annual Meeting of the Midwest Political Science Association, 1999:1-32.

22 The British Society of Gastroenterology. British Society of gastroenterology workforce report, 2019. Available: https://www.bsg org.uk/workforce-reports/workforce-report-2019/ [Accessed 14 Feb 2020].

23 Keswani RN, Keefer L, Surawicz CM. Burnout in Gastroenterologists and how to prevent it. Gastroenterology 2014;147:11-14.

24 Herring M, Forbes Kaufman R, Bogue R. Mentoring to help prevent physician burnout. Health Prog 2016;97:74-7.

25 Harrison R, Hunter AJ, Sharpe B, et al. Survey of US academic hospitalist leaders about mentorship and academic activities in hospitalist groups. J Hosp Med 2011;6:5-9.

26 Ong J, Swift C, Magill N, et al. The association between mentoring and training outcomes in junior doctors in medicine: an observational study. BMJ Open 2018;8:e020721.

27 Lim WY, Ong J, Ong S, et al. The abbreviated Maslach burnout inventory can overestimate burnout: a study of anesthesiology residents. J Clin Med 2019:9:61-14.

28 Sanfilippo F, Noto A, Foresta G, et al. Incidence and factors associated with burnout in anesthesiology: a systematic review. Biomed Res Int 2017:2017:1-10.

29 Schaufeli WB, Bakker AB, Hoogduin K, et al. On the clinical validity of the maslach burnout inventory and the burnout measure. Psychol Health $2001 ; 16: 565-82$. 